\title{
Bardet-Biedl Syndrome: A Rare Cause of Chronic Kidney Disease
}

\author{
Vivek B. Kute • Aruna V. Vanikar • Manoj R. Gumber • \\ Himanshu V. Patel · Pankaj R. Shah · Sachin B. Patil • \\ Hargovind L. Trivedi
}

Received: 31 May 2012/ Accepted: 14 October 2012/Published online: 30 October 2012

(C) Association of Clinical Biochemists of India 2012

\begin{abstract}
Bardet-Biedl syndrome (BBS) is a rare autosomal recessive condition characterized by retinitis pigmentosa, postaxial polydactyly, central obesity, and renal involvement. Renal failure is the commonest cause of death. We report a case of BBS with chronic kidney disease (CKD) at younger age (17 year) from India. This diagnosis should be considered in patients with renal disease and the characteristic phenotype of retinitis pigmentosa, postaxial polydactyly and central obesity. These patients should undergo regular monitoring of renal function test to early diagnosis and treatment of CKD to prevent morbidity and mortality. Renal transplantation is a viable option of renal
\end{abstract}

V. B. Kute $(\bowtie) \cdot$ M. R. Gumber · H. V. Patel

P. R. Shah - S. B. Patil - H. L. Trivedi

Department of Nephrology and Clinical Transplantation,

Institute of Kidney Diseases and Research Center, Dr. HL

Trivedi Institute of Transplantation Sciences IKDRC-ITS, Civil

Hospital Campus, Asarwa, Ahmedabad 380016, Gujarat, India

e-mail: drvivekkute@rediffmail.com

M. R. Gumber

e-mail: drmanojgumber@rediffmail.com

H. V. Patel

e-mail: drhvpate12010@rediffmail.com

P. R. Shah

e-mail: drpankajrshah@yahoo.com

S. B. Patil

e-mail: drsachinbpatil@yahoo.com

H. L. Trivedi

e-mail: ikdrcad1@sancharnet.in

\section{A. V. Vanikar}

Department of Pathology, Laboratory Medicine, Transfusion Services and Immunohematology, IKDRC-ITS, Ahmedabad, India

e-mail: vanikararuna@yahoo.com replacement therapy in these patients. These findings are valuable for comparing phenotype of BBS patients with CKD from various national and international centers.

Keywords Bardet-Biedl syndrome $\cdot$ Chronic kidney disease $\cdot$ Retinitis pigmentosa $\cdot$ Polydactyly $\cdot$ Central obesity

\section{Introduction}

Bardet-Biedl syndrome (BBS) is an autosomal recessive condition characterized by rod-cone dystrophy (retinitis pigmentosa), postaxial polydactyly, central obesity, mental retardation, hypogonadism, and renal involvement. It has prevalence of 1 in 1,40,000-1 in 1,60,000 worldwide [1]. Renal involvement in the form of various structural and functional abnormalities is common and renal insufficiency is noted in $\sim 5-25 \%$, with progression to end-stage renal disease (ESRD) in 4-10\%. ESRD in BBS patients is the final stage of the disease, increasing mortality in youth. Renal insufficiency is noted in $\sim 5-25 \%$, with progression to ESRD in 4-10 \%. ESRD is the most common cause of death in BBS [1]. Only few reports have been described from India regarding ESRD/chronic kidney disease (CKD) in BBS [2-5]. Herein, we report a case of BBS with CKD in a 17 year female from India.

\section{Case Report}

A 17 year old female presented for evaluation of altered renal function test at our institute. She was born to nonconsanguineous parents in 1995 with low birth weight. Her parents noticed progressive decline in vision since 
childhood, presently she developed retinitis pigmentosa with impaired vision since 4 years (WHO category 3 visual impairment). She had no major illness in childhood but had polyuria and polydipsia. She had delayed milestones. She is not a known diabetic/hypertensive. Attained menarche at the age of 13 years and had irregular menstrual history. Scholastic performance was average and educated till tenth standard.

On Examination, she has central obesity (Fig. 1), pallor, polydactyly (upper and lower limb) (Figs. 2, 3). She had no dental anomalies or high arched palate, cardio respiratory and abdominal examination does not reveal any abnormalities. Her vital sign were normal, blood pressure, 110/70 mmHg; weight $69 \mathrm{~kg}$; height $145 \mathrm{~cm}$; and body mass index, $32.8 \mathrm{~cm} / \mathrm{kg}$.

Laboratory investigations revealed hemoglobin, 10.6 $\mathrm{gm} / \mathrm{l}$; total white cell count, $13.6 \times 103 / \mu \mathrm{l}$ (differential count: $70 \%$ neutrophils, $25 \%$ lymphocytes, $2 \%$ monocytes, and $2 \%$ eosinophils); platelet count, $317 \times 105 / \mu 1$; pack cell volume, $33.5 \%$; serum total protein, $7 \mathrm{gm} / \mathrm{dl}$; serum albumin, $4 \mathrm{gm} / \mathrm{dl}$; serum urea, $41 \mathrm{mg} / \mathrm{dl}$; creatinine, $3.37 \mathrm{mg} / \mathrm{dl}$ [Modification of Diet in Renal Disease

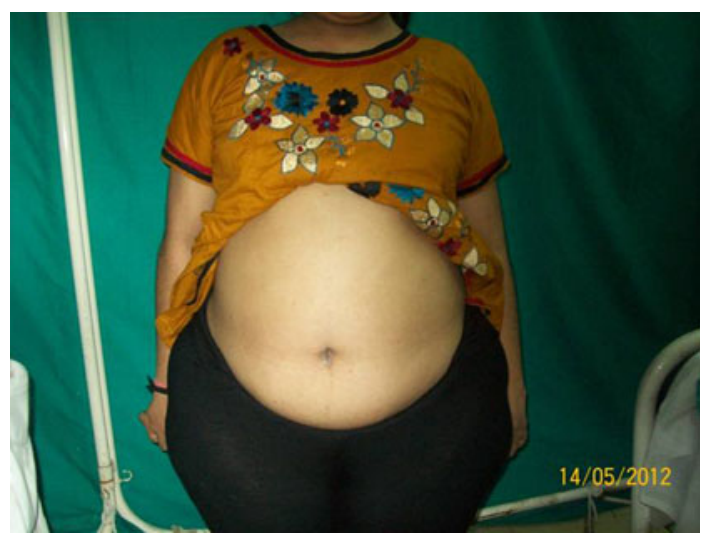

Fig. 1 Showing truncal obesity

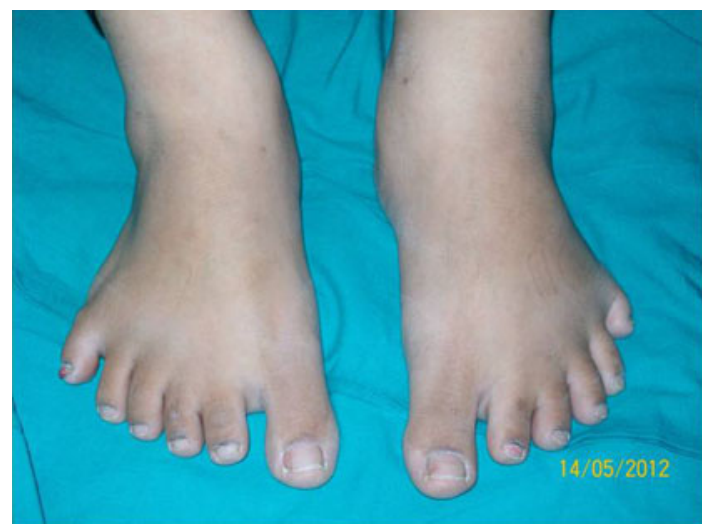

Fig. 2 Showing polydactyly in lower limb

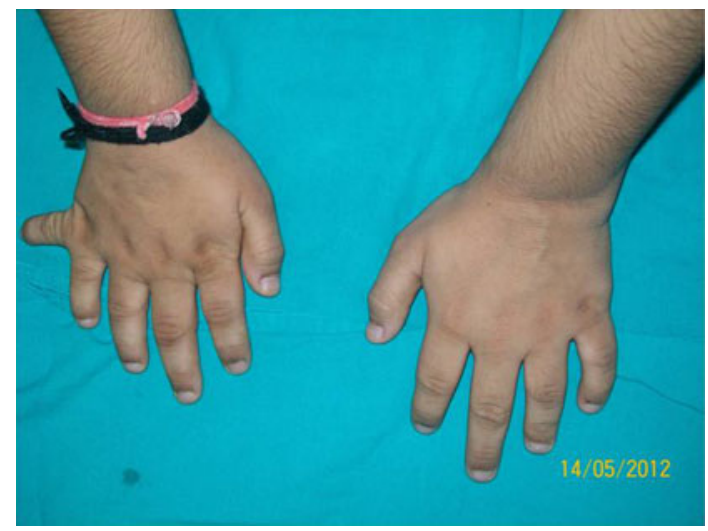

Fig. 3 Showing polydactyly in upper limb

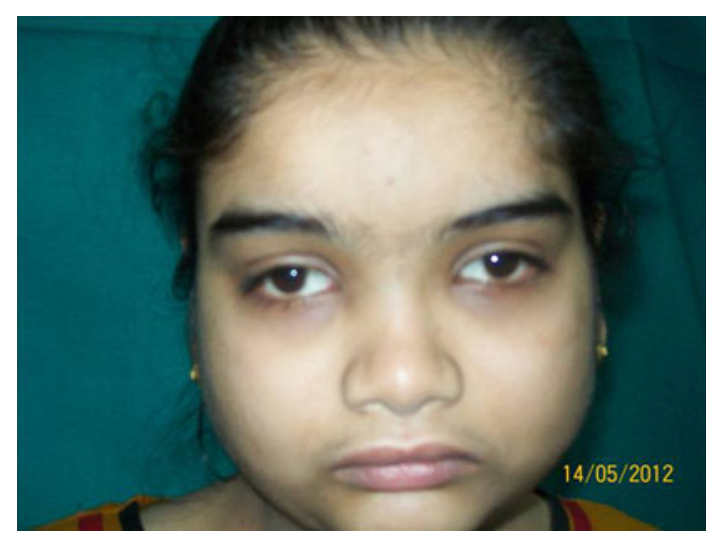

Fig. 4 Showing visual impairment

(MDRD) Study glomerular filtration rate (GFR) value based on 4 variables (age, race, gender, plasma creatinine), $18 \mathrm{ml} / \mathrm{min} / 1.73 \mathrm{~m}^{2}$ ];sodium $142 \mathrm{meq} / \mathrm{l} ; \quad$ potassium $4.2 \mathrm{meq} / \mathrm{l}$; calcium, $10 \mathrm{mg} / \mathrm{dl}$; phosphorus, $6.7 \mathrm{mg} / \mathrm{dl}$; and uric acid $(8 \mathrm{mg} / \mathrm{dl})$.Urine examination showed +1 albumin; specific gravity 1.003 and fasting blood glucose, lipid profile, liver profile were normal. The tests for antinuclear antibody (ANA), anti-double-stranded deoxyribonucleic acid, anti-neutrophil cytoplasmic antibody (c-ANCA/pANCA), were all negative and complement components (C3 and C4) were normal. Enzyme-linked immunosorbent assays test for human immunodeficiency virus, hepatitis B surface antigen and hepatitis $\mathrm{C}$ virus were negative. Fundus examination revealed rod-cone dystrophy (Retinitis Pigmentosa), Fundus image and tomogram done for impaired vision is shown in Figs. 4 and 5.

The ultrasonography of abdomen revealed bilateral contracted kidneys and ovaries are/uterus was normal. Cardiac evaluation echocardiography/electrocardiogram was normal. Hearing evaluation was normal. She is known case of hypothyroid and on tablet levothyroxine sodium, 125 microgram. Her thyroid function tests were normal 
Fig. 5 Showing fundus image and tomogram of retinitis pigmentosa

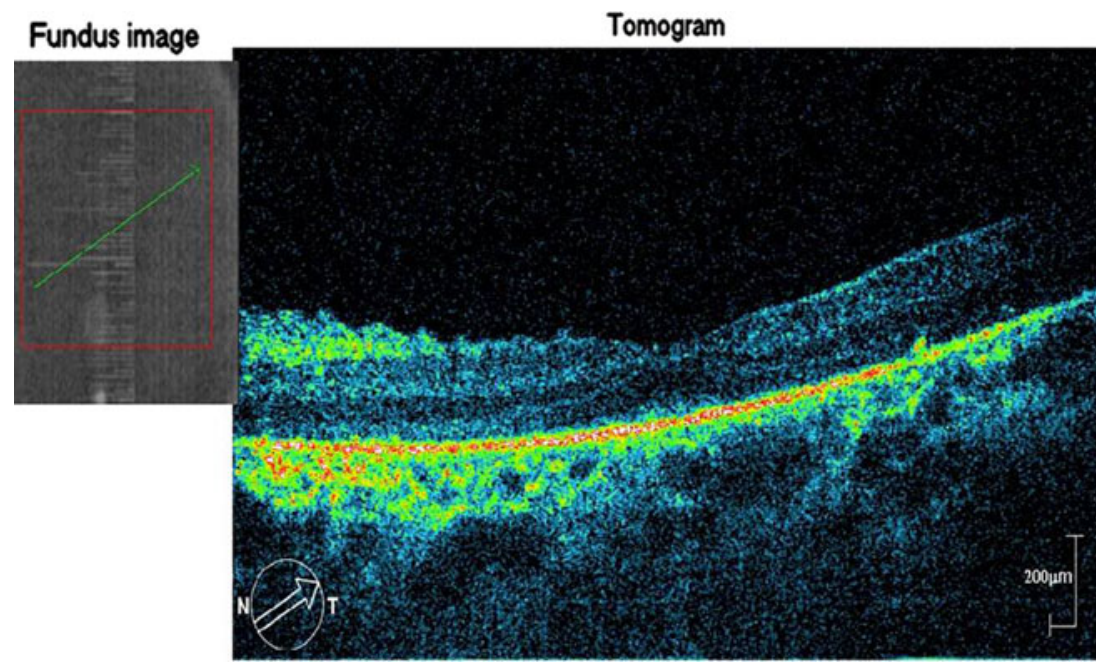

[TSH, 3.5 (normal range, 0.27-4.2 miU/l); T4, 136 (normal range, $66-181 \mathrm{nmol} / \mathrm{l}$ ); $\mathrm{T} 3,1.8$ (normal range, 1.3-3.1 nmol/l) (COBAS chemiluminescence)]. MRI brain and pituitary was normal. Urine examinations for mucoplysachrides were negative. Chromosomal study from whole blood revealed 46 XX karyotype. With all the above clinical and laboratory finding it was diagnosed as BBS with CKD. Blood group of patient was A negative. She is under preparation for renal transplantation with her 35 year mother as donor with blood group $\mathrm{O}$.

\section{Discussion}

On the basis of a review of 109 cases, Beales et al. [1] suggested following the diagnostic criteria for BBS; Major features included retinal dystrophy $(>90 \%)$, post axial polydactyly ( $21 \%$ ), truncal obesity (72\%), hypogonadism (more frequent in males), renal anomalies, chronic renal failure (30-60\%), hypertension (50-66\%). Minor features included learning disabilities, speech delay, developmental delay, behavioural abnormalities, Eye abnormalities, brachydactyly/syndactyly, ataxia, mild hypertonia, diabetes mellitus, orodental abnormalities, cardio vascular anomaly, anosmia .Four major or three major and 2 minor criteria are required for diagnosis.

So far, very few cases have been reported from India, of which only 3 had CKD. Somwanshi et al. [4] reported four cases with the typical phenotypic features of BBS in 1988. Pal et al. and Maheshwari et al. [5, 6] reported five case reports and all had normal renal function. Gupta et al. [3] reported the first case of BBS from India with renal insufficiency (creatinine $3.0 \mathrm{mg} / \mathrm{dl}$ ) in a 20-year-old female who had bilateral hypoplastic kidneys on ultrasound and also had multiple fractures, possibly related to renal osteodystrophy. Hooda et al. [7] reported the first case from India who has undergone successful preemptive living-related renal transplantation with 38 year old mother as the donor in BBS with stage III CKD in a 12-year-old male child presented with obesity, polydactyly, retinitis pigmentosa and hypogonadism. Investigations showed blood urea nitrogen $43 \mathrm{mg} / \mathrm{dl}$, creatinine $4.3 \mathrm{mg} / \mathrm{dl}$ with normal echocardiography, Ultrasound showed small kidneys (right $6.3 \mathrm{~cm}$, left $6.7 \mathrm{~cm}$ ) with loss of cortico-medullary differentiation, mild cortical irregularity diethylene triamine pentaacetic acid (DTPA) scan showed bilateral impaired renal function (GFR right kidney $16.1 \mathrm{ml} / \mathrm{min}$, left kidney $15.8 \mathrm{ml} / \mathrm{min}$, and total GFR $31.9 \mathrm{ml} / \mathrm{min}$ ). He was started on conservative management and underwent amputation of extra digits of hands. He progressed to ESRD in 1 year [creatinine, $11 \mathrm{mg} /$ $\mathrm{dl}$ and calculated GFR of $5.68 \mathrm{ml} / \mathrm{min}]$. Fourteen months post-transplantation, he was asymptomatic with creatinine of $1.1 \mathrm{mg} / \mathrm{dl}$, and DTPA scan GFR of graft kidney of $56.3 \mathrm{ml} / \mathrm{min}$. His maintenance immunosuppression consisted of tacrolimus, mycophenolate mofetil, and prednisolone. Ersoy et al. reported a 20-year-old patient in whom primary central nervous system lymphoma was diagnosed 20 months after renal transplantation. Although a few patients with BBS have been described to develop malignant disease, there was no previous association with lymphoma [8]. Pal et al. [5] has reported an 18-year-old female with pigmentary retinopathy, hypogenitalism, dwarfism, polydactyly, obesity, and mental retardation, but without renal involvement. Prakash [9] reported cysts in the left kidney with normal renal functions, in a 30-year-old patient. Gupta et al. [3] reported of BBS in a 20-year-old female with serum creatinine of $3 \mathrm{mg} / \mathrm{dl}$ and ultrasonography finding of bilateral hypoplastic kidneys and multiple fractures, possibly related to renal osteodystrophy. Jethani et al. [10] reported BBS in a seven-year-old boy presented with impaired vision and multiple systemic anomalies including facial asymmetry, ventricular septal defect, polydactyly and 
hypospadias with mental retardation. The diagnosis of the BBS is often delayed until about 9 years of age when visual problems first appear [11]. BBS was reported in an 11 year boy presented with complaint of excessive weight gain along with central obesity, postaxial polydactyly, mental retardation [IQ, 55], retinitis pigmentosa, hypogonadism, functional renal impairment [proteinuria] and nonalcoholic steatohepatitis. He was prescribed glasses, advised for fat and refined carbohydrate-restricted diet and exercise with careful monitoring for hypogonadism [12]. Dilated cardiomyopathy was incidentally diagnosed during surgical treatment for lower limb fracture in BBS patient [13]. Rathi et al. [14] described the first case from India with ESRD who was treated with continuous ambulatory peritoneal dialysis (CAPD). Sowjanya et al. [2] reported a 16 year old female with ESRD. Prakash [9] reported another 30-yearold patient with BBS who had cysts in the left kidney with normal renal function. ESRD in BBS patients has been reported at age range of 4-57 years [2-5, 15-19].

Management of BBS is supportive and includes training and rehabilitation for blind and mentally retarded patients, hearing aids for deafness, and diet and exercise for obesity. Organizations such as the Foundation Fighting Blindness and the Laurence-Moon-Bardet-Biedl Society provide emotional and social support and help in all-round development. Early and regular screening for hypertension, diabetes, and renal involvement is required.

The management of renal failure in BBS does not differ from that due to any other cause and all three modalities of long-term renal replacement therapy (RRT), i.e., hemodialysis, CAPD, and renal transplantation can be offered to these individuals. Still, it represents a very rare indication for kidney transplantation [7, 8, 15]. Renal transplantation is a viable option of renal replacement therapy in these patients. Genetic counseling is advised for affected individuals. With regard to genotype-phenotype correlation, patients with a mutation in the BBS6, BBS10, or BBS12 gene (10 of 33 patients) had more severe renal disease [8]. Still, it represents a very rare indication for renal transplantation $[8,15,16]$. Such renal transplant patients are known to be at increased risk for the development of severe obesity, malignancies and cardiovascular complications after transplantation [17].

\section{Conclusion}

We report a case of BBS with CKD in a 17 year female from India. This diagnosis should be considered in patients with renal disease and the characteristic phenotype of retinitis pigmentosa, postaxial polydactyly and central obesity. Renal involvement is common and renal failure is most common cause of death in BBS. These patients should undergo regular monitoring of renal function test to early diagnosis and treatment of CKD to prevent morbidity and mortality. Renal transplantation is a viable option of RRT in these patients. These findings are valuable for comparing phenotype of BBS patients with CKD from various national and international centers.

Disclosure Informed written permission and ethical clearance taken from patient to publish case data and photograph.

\section{References}

1. Beales PL, Elcioglu N, Woolf AS, Parker D, Flinter FA. New criteria for improved diagnosis of Bardet-Biedl syndrome: results of a population survey. J Med Genet. 1999;36:437-46.

2. Sowjanya B, Sreenivasulu U, Naidu JN, Sivaranjani N. End stage renal disease, differential diagnosis, a rare genetic disorder: Bardet-Biedl syndrome: case report and review. Indian J Clin Biochem. 2011;26:214-6.

3. Gupta S, Goel D, Singhal A. A rare presentation of Bardet-Biedl syndrome with renal failure, severe osteodystrophy and multiple fractures. Indian J Hum Genet. 2005;11:159-60.

4. Somwanshi PR, Nikam SH, Patni PD. Laurence moon Biedl Bardet syndrome. J Assoc Physician India. 1988;36:333-5.

5. Pal S, Bhattacharyya AR. Laurence-moon-Bardet-Biedl syndrome. J Indian Med Assoc. 1995;93(391):393.

6. Maheshwari S, Porwal R, Joad SH, Goyal RK, Chandak GK. Laurence-Moon-Biedl syndrome. J Assoc Physicians India. 1998; 46:977.

7. Hooda AK, Karan SC, Bishnoi JS, Nandwani A, Sinha T. Renal transplant in a child with Bardet-Biedl syndrome: a rare cause of end-stage renal disease. Indian J Nephrol. 2009;19: $112-4$.

8. Ersoy A, Kahvecioglu S, Bekar A, Aker S, Akdag I, Dilek K. Primary central nervous system lymphoma in a renal transplant recipient with Bardet-Biedl syndrome. Transplant Proc. 2005;37: 4323-5.

9. Prakash EB. Bardet Biedl syndrome. J Assoc Physicians India. 2005;53:781.

10. Jethani J, Parija S, Shetty S, Vijayalakshmi P. Atypical association of Duane retraction syndrome and Bardet Biedl syndrome. Indian J Ophthalmol. 2007;55:139-41.

11. Majumdar U, Arya G, Singh S, Pillai A, Nair PP. Oro-dental findings in Bardet-Biedl syndrome. BMJ Case Rep. 2012;. doi: 10.1136/bcr.12.2011.5320.

12. Sahu JK, Jain V. Laurence-Moon-Bardet-Biedl syndrome. JNMA J Nepal Med Assoc. 2008;47:235-7.

13. Mahajan R, Kumar Batra Y, Kumar S, Kumar Grover V. Anesthetic management of a patient with Bardet-Biedl syndrome and dilated cardiomyopathy. Minerva Anestesiol. 2007;73:191-4.

14. Rathi M, Ganguli A, Singh SK, Kohli HS, Gupta KL, Sakhuja V, et al. Bardet-Biedl syndrome with end-stage kidney disease. Indian J Nephrol. 2007;17:10-3.

15. Noorden G, Friman S, Frisenette-Fich C, Persson H, Karlberg I. Renal transplantation in the Bardet-Biedl syndrome, a form of Laurence-Moon-Biedl syndrome. Nephrol Dial Transplant. 1991;6:982-3.

16. Mihai CM, Marshall JD, Stoicescu RM. Bardet-Biedl syndrome with end-stage kidney disease in a four-year-old Romanian boy: a case report. J Med Case Rep. 2011;5:378.

17. Imhoff O, Marion V, Stoetzel C, Durand M, Holder M, Sigaudy S, Sarda P, Hamel CP, Brandt C, Dollfus H, Moulin B. Bardet- 
Biedl syndrome: a study of the renal and cardiovascular phenotypes in a French cohort. Clin J Am Soc Nephrol. 2011;6:22-9.

18. Devarajan P. Obesity and genitourinary anomalies in BardetBiedl syndrome after renal transplantation. Pediatr Nephrol. 1995;9:397-8.
19. Langer RM, Földes K, Szalay L, Járay J. Laurence-Moon-BardetBiedl syndrome for kidney transplantation at the age of 57 years. Transplant Proc. 2005;37:4223-4. 